\title{
Neoliberalismo, Políticas de Gênero e feminicídio na América Latina
}

\author{
Neoliberalism, Gender Policies and feminicide in Latin America
}

DOI: https://doi.org/10.22456/2178-8839. 113519

Kathleen Kate Dominguez Aguirre Universidade do Vale do Rio dos Sinos, São Leopoldo, Brasil katedominguezaguirre@gmail.com

\section{Resumo}

Há 30 anos cresce exponencialmente o número de feminicídios na América Latina, paralelamente aos projetos e acordos neoliberais feitos nos países da região em benefício do Norte Global, sobretudo das potências dominantes na política internacional. No mesmo período, violência de gênero e direitos das mulheres ganham centralidade em programas originados ou mediados por organismos de cooperação internacional, especialmente a Organização das Nações Unidas - ONU, debatendo e institucionalizando nos países signatários medidas paliativas para as consequências decorrentes dos projetos que estes próprios organismos implantaram no Sul Global. Nesta conjuntura, evidencia-se e problematiza-se a crescente dos feminicídios na América Latina apesar das agendas humanitárias da cooperação internacional e países do Norte Global, a partir de teóricas/os do Sul Global, sob perspectiva decolonial e metodologia de análise regressiva-progressiva. Conclui-se que a combinação entre abordagem reformista de pautas feministas e política s neoliberais implicam exploração e/ou morte de mulheres latino-americanas e perpetuam a dependência geopolítica moderna/colonial.

Palavras-chave: Neoliberalismo; Feminicídio; América Latina;

\begin{abstract}
The number of feminicides in Latin America has grown exponentially over the past 30 years, in parallel to the neoliberal politics and agreements made in the countries of the region, for the benefit of the Global North, especially the dominant powers in international politics. In the same period, gender violence and women's rights came centre stage in programs originated or mediated by international organisations, especially the United Nations - The $\mathrm{UN}$, debating and institutionalising for the member countries, trying to alleviate the consequences resulting from the ideologies that these very organisations implemented to the Global South. With this state of affairs, the increasing feminicide in Latin America, despite the humanitarian agendas of international cooperation and the countries of the Global North, has highlighted and problematised, based on theories from the Global South, under a decolonial perspective and regressive-progressive analysis. We conclude that the combination of a reformist approach to feminist agendas and neoliberal policies implicates the exploitation and/or death of Latin American women and perpetuate modern/colonial geopolitical dependence.
\end{abstract}

Keywords: Neoliberalism; Feminicide; Latin America;

Recebido: 29 abril 2021

Aceito: 01 setembro 2021 


\section{Introdução}

Entre os 17 Objetivos de Desenvolvimento Sustentável - ODS da agenda acordada pela Organização das Nações Unidas (ONU) em 2015, estáinclusa a Igualdade de Gênero que propõe "acabar com todas as formas de discriminação contra todas as mulheres e meninas em toda parte" (UNICEF, 2015). Esta meta articula o Programa de Ação da Conferência Internacional sobre População e Desenvolvimento de 1994 e a Plataforma de Ação da IV Conferência Mundial sobre a Mulher de 1995.

Há uma continuidade nos acordos e projetos internacionais de políticas públicas com vistas à equidade de gênero e à extinção da violência contra mulheres. Contudo, de 1990 para cá, desde que organizações de mulheres centroamericanas passaram a utilizar o termofeminicídio para denunciar e reivindicar justiça pela morte sistemática de mulheres por razões de gênero, os índices desse crimenão só se elevaram, como alcançaram picos alarmantes e configurações brutais se disseminando aolongo da América Latina (SEGATO, 2005).

Se há esforços da política internacional em combater estes tipos de crime e o compromisso das nações do Norte Global com obem-estar e a vida das mulheres latino-americanas, por que cada vez mais o gênero feminino segue morrendo violentamente na América Latina - em vida, pelo medo e terror de ser mulher cis/trans ou travesti ${ }^{1}$, e biologicamente, por meio de golpes, facadas, tiros, apedrejamentos, incinerações, espancamentos e alto nível de crueldade?

Não há respostas consolidadas para este problema angustiante, masneste artigo busca -se contemplá-lo situando o fenômeno do feminicídio na América Latina sob uma perspectiva do Sul Global (CONNEL, 2012), propondo uma abordagem que articule a teoria decolonial (QUIJANO, 2005; MALDONADO-TORRES, 2019) ao método marxiano de análise regressiva-progressiva (PRATES, 2012), ou seja, no próprio movimento histórico-dialético de constituição dos feminicídios no Sul Global como um fenômeno necessário à configuração e manutenção do sistema-mundo moderno/colonial, tendo em vista, portanto, indagar formas de combate quelevem em conta a matriz econômica e política destas mortes.

Com esta finalidade, discute-se o marco teórico e possíveis chaves analíticas do feminicídio como mecanismo moderno/colonial e problematiza-se em que medida políticas de gênero hegemônicas contribuem para o combate à violência contra as mulheres do Sul Global, em especial as latino-americanas. Para tanto, problematiza-se de forma introdutória as contradições entre objetivos das agendas globais dirigidas pela ONU e de seus programas hum anitários com enfoque em gênero desenvolvidos em parceria com governos nórdicos, e as reformas neoliberais impostas pelas suas agências e tratados - dos quais são beneficiários os países dominantes da política mundial e seus aliados do Norte. A conclusão retoma o conjunto deste debate propondo delineamentos analíticos sobre o fenômeno na América Latina.

\section{Feminismo e neoliberalismo: uma contradição que mata}

O processo de produção científica tem uma condição geopolítica que, em geral, pressupõe uma divisão social do trabalho, onde o Norte Global produz teorias a serem aplicadas na periferia colonizada (CONNELL, 2012). Esse modelo é exportado para o Sul Global como uma bomba cultural (BERNARDINO-COSTA; MALDONADO-TORRES; GROSFOGUEL, 2019). E, desta forma, a inclusão do que é “diferente” nas teorias atuais depende de um confronto deste aparato hegemônico, o que implica a desestabilização e relocalização do centro geopolítico a partir das produções da periferia global. Neste sentido, o conjunto de autores/as com os quais dialoga-se a seguir situa-se predominantementenas Teorias do Sul Global, como projeto político-epistêmico integrado à experiência intelectual e política do colonizado (GROSFOGUEL, 2008).

\footnotetext{
${ }^{1}$ Cisgênero é a pessoa que se identifica com o gênero designado no nascimento. Pessoas transexuais e transgênero são as que não se identificam com o sexo e/ou gênero designado a si quando do seu nascimento. Já as travestis são pessoas que não se reconhecem dentro do sistema binário mulher/homem, sendo assim membros de um terceiro-gênero (Nogueira; Aquino; Cabral, 2017).
} 
A descoberta do Novo Mundo é, para os decoloniais, o marcador antropoceno da modernidade devido a sua relação global de colonização que fundou um sistema -mundo moderno (QUIJANO, 2005; MALDONADO-TORRES, 2019). A experiência colonial iniciada neste período também implicou lutas descolonizadoras nos territórios dominados, posteriormente convertidas em teorias fundamentais sobre os impactos deste encontro nas sociedades modernas (CONNELL, 2012).

Contudo, as lutas por libertação não necessariamente foram capazes de romper com as estruturas coloniais, implicando na manutenção de poderio das antigas Metrópoles através de novasformas culturais e econômicas de domínio e controle do sistema-mundo moderno/colonial, ou seja, de um aparato chamado colonialidade(GROSFOGUEL, 2008).Já decolonialidade “[...] refere-se à luta contra a lógica da colonialidade e seus efeitos materiais, epistêmicos e simbólicos” (MALDONADO-TORRES, 2019, p.36), sem romper com a modernidade, mas buscando superá-la, podendo manter ou ressignificar alguns de seus elementos. Esta resposta à colonialidade só estará apta se houver rompido a relação de assimilação colonizador/colonizado.

Nestes termos, uma investigação decolonial do feminicídio na América Latina deve transformar a análise de gênero, descortinando sua colonialidade, através da compreensão das vozes na política de gênero que, na periferia global, está entrelaçada às dinâmicas de colonização e globalização; do pressuposto de que o poder colonial intencionalmente e violentamente estruturou a ordem de gênero nas sociedades colonizadas; do entendimento basilar de que as dinâmicas de gênero são coletivas e não podem ser reduzidas ao indivíduo (CONNELL, 2016).

Neste esquema, gênero é uma estrutura multidimensional que padroniza os arranjos pelos quais grupos e indivíduos atuam socialmente, mas que é mutável, se adapta e reinventa conforme demandas e crises sociais, políticas e econômicas. Gênero, portanto, está em disputa e perspectivas feministas decoloniais e devem tomar cuidado com as expectativas das inclinações reformistas, uma vez que intervenção neoliberal e cooptação de pautas identitárias são processos interconectados que desmantelam e evitam organizações políticas ameaçadoras ao sistema de dominação, adaptando-as ideologicamente às agendas hegemônicas. Analisar feminicídio depende, portanto, de compreender suas relações e políticas também em escal a global, entendendo como economias, territórios e Estados sãogenerificados “[...] na era das empresas transnacionais, da internet e da política global neoliberal” (CONNELL, 2016, p.42).

Tendo isso em vista apontou-se a Igualdade de Gênero como um dos 17 ODS da Agenda 2030 que sucedem os Objetivos de Desenvolvimento do Milênio - ODM, acordados pela ONU no final da década de 1990 com foco nos países considerados "em desenvolvimento", especialmente os mais pobres, e com prazo expirado em 2015. A Agenda 2030 amplia a esfera de ação e investimento do/no setor privado, propondo reformas estruturais sob a liderança dos países considerados desenvolvidos. Curiosamente, há um antagonismo entre as metas da ONU - manutenção da paz e da segurança internacional através da erradicação da pobreza, da fome zero e da agricultura sustentável, educação de qualidade, acesso à água potável, desenvolvimento econômico e industrial, conservação do meio ambiente etc - e as práticas e interesses dos países dominantes que compõem permanentemente seu Conselho de Segurança, especialmente os EUA.

Nos antecedentes desta agenda, muitos acordos foram feitos no âmbito da política e da economia internacional tendo por finalidade manter a desigualdade a nível global. Por exemplo, os acordos e imposições do FMI e do Banco Mundial aos países do Sul Global, denominados pelo Norte como “em desenvolvimento", especialmente na África e na América Latina na década de 1980 (FEDERICI, 2019; CONNEL; PEARSE, 2015). O Tratado Norte-Americano de Livre Comércio (NAFTA) e a Rodada Uruguai e agências como a Organização Internacional do Trabalho (OIT), a Organização do Comércio Mundial (OCM), a Conferência das Nações Unidas sobre Comércio e Desenvolvimento (UNCTAD) e o Escritório de Coordenação de Assuntos Humanitários (OCHA) sempre favoreceram as potências mundiais em detrimento do Sul Global a partir de programas que supostamente visam seu desenvolvimento (BATISTA, 1992; SANTOS, 2017; GONÇALVES, 2018). E a ONU é a principal matriz destes tratados, além de também responsável pela sua manutenção, como podemos 
identificar na própria citação compromissada dos ODS às suas versões contemporâneas e órgãos competentes, como o projeto Doing Business, o Acordo TRIPS e as propostas do relatório Um AjusteJusto em 2017.

Pode ser uma organização ao mesmo tempo comprometida com as reformas trabalhista e previdenciária no Brasil e a erradicação da pobreza, o bem-estar e a vida de mulheres latino-americanas (KRAWCSUN; GOMES; SOUZA, 2020; FIDELES, 2019)? Problematizando estas contradições, podemos tomar como exemplo a articulação entre a ONU Mulheres, as Embaixadas Nórdicas, a Universidade de Brasília-UnB, ONG’s e pesquisadoras feministas na concretização do projeto Diálogos Nórdicos (2020) que debateu em 2018 os benefícios da equidade de gênero para a economia, a política e o bem-estar social com base nos ODS para 2030. Ao final deste mesmo ano a Suécia lançou o Manualde Política Externa Feminista, sendo que desde 2014 adota uma política externa voltada para mulheres, que na Bolívia teria gerado mais de 500 empregos autônomos e no Chile campanhas para igualdade de gênero com foco nos homens. Além disso, no 08 de março de 2020 os Primeiros-Ministros Nórdicos afirmaram estar comprometidos em proteger os direitos das mulheres (SOLBERG et al, 2020).

Com base na sua experiência ${ }^{2}$, feministas nórdicas sugerem a interrupção do pessimismo sobre o Estado, argumentando que a combinação entre os movimentos feministas de base e leis estatais propiciaram políticas públicas e regimes favoráveis à igualdade de gênero nos seus países de origem (CONNELL \& PEARSE, 2015; MOTTA; CAMPOS, 2020). Discutindo esta alternativa para o Sul Global, argumenta-se aqui que se origina de um posicionamento geopolítico antagônico às experiências de mulheres latino-americanas.

Por exemplo, atualmente a América Latina integra o eixo periférico da política e economia internacional. Suas pequenas e médias nações "possuem recursos humanos, agrícolas ou minerais abundantes (inclusive energia), mas não detém capacidade militar de articulação diplomática, tendendo a agir de maneira fragmentada e constituindo uma zona em disputa pelos demais eixos” (VISENTINI, 2019, p.16-17). Sendo território em potencial para investimentos lucrativos na área da infraestrutura, mineração, serviços, agronegócios e Defesa, frágil e debilitado política, social, militar e economicamente, torna-se palco de crescente "[...] competição intercapitalista, o qual opõe, principalmente, as antigas potências industriais e as emergentes da semiperiferia” (VISENTINI, 2019, p.17), conflito protagonizado especialmente por EUA e China (o primeiro tentando interromper o avanço e influência do segundo, ambos membros permanentes do Conselho de Segurança da ONU).

Esta fragilidade dos países periféricos implica que suas agendasinternacionais se resumam “[...] à manutenção de sua existência como nação e das elites locais no poder” (VISENTINI, 2019, p.7). Dentre estes o Brasil, integrante do BRICS $^{3}$ desde 2006, está oscilando devido às crises governamentais, econômicas e sanitária, correndo o risco de ser rebaixado definitivamente para o eixo periférico e tornar-se um dos seus membros gigantes na América Latina.

Por sua vez, a Dinamarca está entre os países associados ao grupo dominante da política mundial (formado por EUA, Canadá, Reino Unido, Austrália e Nova Zelândia). Embora este e outros países nórdicos, como a Noruega, a Suécia e a Finlândia, sejam representados como modelo de políticas por equidade de gênero, sustentabilidade ambiental e economia, ainda nos anos 2000 eles também estavam entre os países europeus que mais consumiam a cocaína proveniente dos cartéis de drogas situados na América Latina (SANTOS; RINALDI, 2011), que mais importavam mulheres e crianças em situação de tráfico sexual (DIAS, 2005), predominantemente latino-americanas e que, mesmo que de forma intermediária entre os países dominantes e periféricos do mercadoglobal, exploram recursos naturais e a mão-de-obra desta região por meio da instalação de empresas transnacionais nos seus territórios (VISENTINI, 2019).

\footnotetext{
${ }^{2}$ Em países como Noruega, Suécia, Dinamarca e Finlândia, que se organizaram em torno de regimes de welfare states social-democratas, as pautas de movimentos feministas foram adotadas conforme as demandas do mercado corporativo, e das disputas entre partidos conservadores, cristãos e liberais, aumentando o acesso de mulheres ao mercado de trabalho através da oferta de serviços públicos para o cuidado, para além da saúde e educação. Contudo, isso não impactou estruturalmente nas relações e divisões de trabalho em gênero. As mulheres, em geral, passaram a ocupar postos de trabalho em serviços sociais e nas áreas das Ciências Humanas, mantendo a figura e papel da mulher como majoritariamente pertencente ao âmbito da reprodução e do cuidado, enquanto os homens permaneceram nas áreas da economia e das Ciências Exatas (MOTTA; CAMPOS, 2020) .

${ }^{3}$ Grupo de países considerados emergentes ou semiperiféricos, composto por Brasil, Rússia, Índia, China e África do Sul.
} 
Retrocedendo um pouco mais, entre os anos de 1996 e 1998 desenvolveu -se uma pesquisa sobre violência doméstica em 16 comunidades latino-americanas com mulheres afetadas pela violência intrafamiliar e agentes de serviços estatais de atendimento a estas mulheres (SAGOT, 2000). Intitulada Ruta Crítica de las mujeres afectadas por la violencia intrafamiliar en América Latina (SAGOT, 2020), a investigação foi coordenada pelo Programa Mulher, Saúde e Desenvolvimento da OPS/OMS ${ }^{4}$ e financiada pelos governos da Suécia e da Noruega.

Foi um trabalho relevante para o tema, devido à abrangência internacional na América Latina, a metodologia qualitativa, a análise desde a experiência das mulheres vítimas, assim como dos avanços e obstáculos institucionais no tratamento deste problema social, fornecendo um panorama da violência doméstica que pode culminar no feminicídio íntimo. Contudo, destacam-se também na investigação alguns impasses relacionados à matriz moderna/colonial da violência de gênero e, por continuidade, dofeminicídio na América Latina e das suas vias de combate estatais.

O primeiro problema emergente é que, embora discuta as problemáticas institucionais deste caminho trilhado pelas mulheres em situação de violência, trata de uma abordagem individualista com solução punitivista. Disso deriva o segundo problema, que é próprio desta via internacional de combate às violências de gênero. Está no fato de que os direitos humanos dessas mulheres estão edificados não no direito à dignidade humana, mas na lógica da economia do mercado mundial, de ter uma vida saudável para trabalhar. Ou seja, enquanto nos países nórdicos as políticas estatais de gênero combinaram demandas feministas de divisão do trabalho doméstico e acesso ao mercado de trabalho aos critérios dos partidos cristãos, conservadores e liberais sobre a atuação pública de mulheres, na América Latina o manejo das pautas se deu em torno da violência de gênero, também conforme concessões de organismos internacionais e da Igreja Católica, orientadas para o trabalho reprodutivo e a exploração da mão de obra das mulheres pobres, ocultando a violência letal contra mulheres, conectada a outras redes ilegais, como a de drogas e de tráfico sexual, que suprem o consumo do Norte Global.

Com este histórico, é irônico que feministas do Sul inspirem-se nos feminismos escandinavos, porque as mulheres de lá se beneficiam do terror e da exploração que cerceia a vida e a liberdade das mulheres daqui; porque as políticas por equidade de gênero destes países estão centradas na unidade familiar que provém de valores tradicionais brancos europeus e, portanto, alheios à realidade latino-americana; disso se depreende a reprodução dos paradigmas do Norte como civilização e dos países do Sul como eternas colônias a serem civilizadas pelos europeus - hoje estendida aos EUA e sua máscara humanitária;e, por fim, encobre o fato de que, embora modelos de políticas corretivas de gênero, países como Suécia e Dinamarca e outros nórdicos como a Finlândia, possuem as mais altas taxas de violência de gênero física e sexual da Europa (BLANCO, 2017). ${ }^{5}$

Neste cenário e devido à crescente violência letal contra mulheres nos últimos 30 anos, pensar a realidade das mulheres latino-americanas depende de situarmos as políticas neoliberais como produto do colonialismo histórico (BROWN, 2019). Atualmente, o sistema neoliberal faz com que "[...] empresas menores, que su prem as maiores ou operam nos nichos que estas deixam abertos, operem em mercados informais de trabalho e somem a maioria dos empregos industriais das mulheres” ${ }^{6}$ (CONNELL \& PEARSE, 2015, p.277). Para tanto, este processo foi revigorado pelos projetos desenvolvimentistas e pesquisas sobre as relações de gênero instrumentalizados através da cooperaçãointernacional em parceria com feministas do Sul.

\footnotetext{
${ }^{4}$ Organização Pan Americana da Saúde/ Organização Mundial da Saúde

${ }^{5}$ Estendendo esta análise a países do Sul Global, Colômbia e Chile, assim como a Dinamarca, são considerados aliados regionais das potências dominantes, especialmente por sua localização estratégica para a área da Defesa, sendo os EUA a liderança do eixo com controle quase exclusivo das Organizaçõe s Internacionais (VISENTINI, 2019). Na América Latina estes mesmos países andinos estão entre os modelos de governança com foco nas políticas de gênero (CAF, 2019). Por sua vez, também estão entre os países com alto índice de assassinatos de mulheres e população trans por razões de gênero na América Latina, sendo que a Colômbia está entre os líderes mundiais de feminicídios, e o Chile, apesar das reformas e políticas contra a violência de gênero - sejam culturais ou legislativas - mantém sua taxa de feminicídios no mesmo nível que a da Colômbia, sem sofrer grandes alterações nos números absolutos (UNICEF/CEPAL, 2020; ARCE; CHAUD, 2020).

${ }^{6}$ As adaptações nas palavras grifadas são minhas, para fins de concordância.
} 
A manipulação destas políticas combinada à segunda onda neoliberal evidencia uma conexão direta entre as reações masculinistas e seus ataques explícitos aos direitos humanos e à política neoliberal, tornando "[...] invisíveis as normas e as desigualdades sociais geradas pelos legados da escravidão, do colonialismo e do patriarcado” (BROWN, 2019, p.55). Mas como isso impacta na morte das mulheres latinoamericanas?

Na América Latina está concentrado o crescimento demográfico mundial, representando tanto uma mão de obra reserva e mercado consumidor, quanto crises migratórias como a ilustrada pela fronteira EUA-México (VISENTINI, 2019). Na lógica do mercado neoliberal, isso exige o manuseio e controle das formas de viver e morrer neste eixo periférico, conforme as demandas e configurações das grandes potências do poder internacional. Isso fica bem ilustrado pelos altos índices de feminicídios e transfeminicídios não-hegemônicos ${ }^{7}$ na fronteira entre Estados Unidos e México (SEGATO, 2005; VALENCIA, 2010), no pacífico colombiano (LOZANO-LERMA, 2016) e no Brasil (BENEVIDES; NOGUEIRA, 2020).

Inclusive a Bolívia, receptora de pesquisas e projetos por equidade financiados pela Suécia desde a década de 1990, está entre os países com maior taxa de feminicídios da América Latina, ficando atrás de Honduras e Salvador (UNICEF/CEPAL, 2020).Já o México, que lidera este ranking junto a Brasil em números absolutos e acompanha a Bolívia na taxa de assassinatos de mulheres, teve os casos de feminicídios disparados após a assinatura do NAFTA, acordado entre EUA, México e Canadá em 1994, sendo que só em Ciudad Juárez houve um aumento de $700 \%$ destes crimes entre 1993 e 2001. Este histórico implicou na Lei Geral de Acesso das Mulheres a uma vida livre de Violência, promulgada em 2007. Contudo, mesmo passada mais de uma década, continuam subindo os índices de feminicídio no país, sendo que entre 2017 e início de 2020 houve um aumento de $137 \%$ dos casos (TORRE, 2020).

No Brasil, o quinto país do mundo que mais mata mulheres (WAISELFISZ, 2015), e líder no assassinato de pessoas trans e travestis - majoritariamente do gênero feminino (LAGATA; BALZER; BERREDO, 2016; BENEVIDES; NOGUEIRA, 2020) - o número de mulheres assassinadas entre 1980 e 2010 teve uma elevação de 217,6\% (IPEA; FBSP, 2020). Estes dados também evidenciam a elevação de $46 \%$ dos assassinatos de mulheres entre 1990 e 1996 . Embora a taxa tenha caído em 2007 (logo após a promulgação Maria da Penha), desde2008 voltou a crescer. Mesmo com a criação da Lei do Feminicídio em 2015, os números seguiram crescendo exponencialmente (IPEA; FBSP, 2020).

Não é possível afirmar a proporção exata dentre as cifras de homicídios que corresponde à imputação de feminicídio, devido à subnotificação dos casos. Considerando também as mortes de mulheres consequentes de tortura, estupro, lesões corporais, suicídios em contexto de extrema opressão de gênero, encontro de cadáveres em locais públicos ou desaparecimento de mulheres, pressupõe-se que há muitos casos ainda não notificados e/ou ocultos nas cifras hegemônicas de feminicídios.

Contudo, o cruzamento de dados sobre o homicídio de mulheres no Brasil entre os anos de 2007 e 2017 identificou que $28,5 \%$ dos crimes ocorreram dentro da residência e 10,7\% tiveram olocal de ocorrência ignorado, além de que houve um aumento de 29,8\% do homicídio de mulheres com utilização de armas de fogo dentro das residências no decênio analisado, com elevação acentuada entre 2015 e 2017. Estas mortes relacionadas à elevação de registros de feminicídios pelas Polícias e à literatura internacional sobre o fenômeno, levam à previsão de que muito provavelmente decorreram da violência doméstica, configurando sua maioria em feminicídio íntimo (IPEA/FBSP, 2019).

Além da subnotificação de dados do assassinato de mulheres cis no Brasil, considera-se também que seus números são distorcidos por não serem contabilizados os transfeminicídios. A falta de registro destes casos dificulta o diagnóstico mascarando os números reais, sendo que quase todas as vítimas são mulheres trans ou travestis e a maioria dos crimes é consumado nas ruas, um cenário comumente ignorado pelas reformas e políticas de gênero propostas por organismos e corporações internacionais (BENEVIDES; NOGUEIRA, 2020).

Com base nos critérios da II Convenção da ONU de 1948, Jesus (2013) considera o cenário de violência letal contra pessoas trans no Brasil como um tipo de genocídio (JESUS, 2013). O feminicídio com caráter genocida também já 
foi retratado na história com a caça às bruxas na Europa do séculoXVI que promoveu “[...] a construção de um novo papel feminino para a nova disciplina do trabalho capitalista” (FEDERICI apud MENEGHEL; LOZANO, 2017, p.121).

Mesmo os feminicídios íntimos (cometidos geralmente por companheiros ou ex-companheiros), considerados pela ONU como a maioria dos casos na América Latina e apontados como consequência da violência doméstica pela pesquisa das Rotas Críticas, também se concretizam através de valores revitalizados pela moralidade e racionalidade neoliberal (BROWN, 2019; FEDERECI, 2019). Para os países do Sul, esta conjuntura pode significar uma resposta imperialista para “[...] uma nova ordem da exploração capitalista, com o propósito de reverter as derrotas sofridas com a luta anticolonial e controlar as riquezas do mundo" (FEDERICI apud MENEGHEL, 2017; LERMA, 2017, p.121).

Desta forma, o fenômeno do feminicídio e sua crescente na etapa neoliberal do capitalismo, com tipos diversos desta violência, caracterizaria uma sistemática de gênero específica para os territórios colonizados que se produz da/na relaçãoinextricável entre as estruturas de nível global e estatal de poder e nível subjetivo destinando mulheres e travestis “[...] à morte, para que em seu corpo o poder soberano grave sua marca; nesse sentido, a morte desses escolhidos para representar o drama da dominaçãoé uma morte expressiva, não uma morte utilitária” (SEGATO, 2005, p.271).

\section{Considerações finais}

Salientou-se neste texto o caráter contraditório do ODS Igualdade de Gênero e de políticas externas feministas promovidas pelo Norte Global que, financiadas por poderosas corporações transnacionais, por um lado afirmam promover acesso à educação, saúde e trabalho para mulheres, e por outro financiam a indústria e o mercado que explora massivamente a mão-de-obra das mulheres pobres e não-brancas do Sul Global, para além de ocultar o feminicídio como meio de manutenção da submissão e dependência do Sul ao Norte.

Para tanto, expôs-se brevemente as origens da violência de gênero, sob uma perspectiva decolonial e metodologia marxiana, buscando no encontro colonial a matriz das relações contemporâneas. Em seguida, levando em conta a conjuntura discutida, argumentou-se que o bem-estar social e a paridade de gênero de países do Norte - e aqui citados como exemplo os nórdicos - se produz em detrimento das condições de vida e de morte de mulheres latinoamericanas. Isso evidencia a capacidade das organizações internacionais de, no antetempo dos movimentosfeministas do Sul, regularem o combate da violência às mulheres na América Latina desde as agendas das potências dominantes.

A combinação entre os feminismos hegemônicos do Norte e as políticas neoliberais institucionalizadas através das agendas globais (operadas pela ONU e orientadas a atender demandas do eixo dominante e seus países associados na política internacional), por trás da judicialização da violência de gênero que evoca reformas através da punição dos sujeitos e responsabilização pautada no comportamento, ocultou sua matriz individualizando o fenômeno e até mesmo perpetuando estruturas e relações violentamente generificadas e a dependência política, econômica, intelectual e cultural entre países do Norte e do Sul. Se violência de gênero e neoliberalismo são complementares, o compromisso feminista de combate aos feminicídios e de liberação das mulheres e travestis latino-americanas é antagônico às estruturas moderno/coloniais e capitalistas e, assim sendo, sua resposta deveria ser de resistência ao sistema-mundo moderno/colonial.

\section{Referências}

ARCE, Yoselin Fernandéz; CHAUD, Isadora Castillo. Dossier informativo: 2019-2020. Violencia contra las mujeres en Chile. Coordinación Nacional Red Chilena contra la Violencia hacia las Mujeres, 2020. Disponível em http://www.nomasviolenciacontramujeres.cl/wp-content/uploads/2020/08/dossier-red-corre.pdf. Acesso em 28.04.2021.

BATISTA, Paulo Nogueira. Perspectivas da Rodada Uruguai: implicações para o Brasil. Estudos Avançados, São Paulo, v.6, n.16, p.103116, 1992. Disponível em https://www.scielo.br/pdf/ea/v6n16/v6n16a09.pdf. Acesso em 28.04.2021. 
BERNARDINO-COSTA, Joaze; MALDONADO-TORRES, Nelson; GROSFOGUEL, Ramón. Decolonialidade e pensamento afrodiaspórico. Belo Horizonte: Autêntica Editora, 2019.

BLANCO, Silvia. O paradoxo da Suécia, um paraíso da igualdade com uma enorme taxa de violência machista. El País, 11.03.2017. Disponível em https://brasil.elpais.com/brasil/2017/03/09/eps/1489066869_454079.html Acesso em 28.04.2021.

CAF. Banco de Desarrollo de América Latina. Modelos de gobernanza con enfoque de equidad de género e inclusión para las comisiones regionales de competitividad de los departamentos de Antioquia, Atlántico, Caldas, Cundinamarca (Bogotá D.C.), Magdalena, Meta, Santander y Valle del Cauca, y fortalecimiento de las capacidades de los miembros de estas comisiones en estructuración, seguimiento y evaluación de proyectos, formulación y análisis de indicadores, así como en equidad de géneroe inclusión para la competitividad, teniendo en cuenta las características particulares de cada departamento. Corporación Andina de Fomento, Banco de Desarrollo de América Latina, 2019. Disponível em https://www.caf.com/media/2244204/tdr-modelos-degobernanza-con-enfoque-de-equidad-de-genero.pdf. Acesso em 26.11.2020.

CONNELL, Raewyn. A iminente revolução na Teoria Social. Revista Brasileira de Ciências Sociais, vol.27, n.80,p.9-20,2012. Disponível em: https://www.scielo.br/scielo.php?script=sci_arttext\&pid=S0102-69092012000300001. Acesso em 27.04.2021.

CONNELL, Raewyn. Gênero em termos reais. São Paulo: nVersos, 2016.

CONNELL, Raewyn; PEARSE, Rebecca. Gênero: uma perspectiva global. São Paulo: nVersos, 2015.

DIÁLOGOS NÓRDICOS. Brasil. Disponível em https://www.dialogosnordicos.com/. Acesso em 28.04.2021.

DIAS, Cláudia Sérvulo da Cunha [coord.]. Tráfico de pessoas para fins de exploração sexual. Brasília: OIT, 2005.

FIDELES, Soraya. Mulheres e Reforma da Previdência. UFMG, Belo Horizonte, 08.05.2019. Disponível em https://ufmg.br/comunicacao/noticias/mulheres-e-reforma-da-previdencia. Acesso em 28.04.2021.

FEDERICI, Silvia. O ponto zero da revolução: trabalho doméstico, reprodução eluta feminista. São Paulo: Elefante, 2019.

GONÇALVES, Rafaella Dias. Abordagem Crítica sobre o Acordo TRIPS e o acesso a medicamentos. In.: PIDCC, Aracaju, v.12, n.1, p.91-110, 2018. Disponível em http://www.pidcc.com.br/artigos/022018/04022018.pdf. Acesso em 28.04.2021.

GROSFOGUEL, Ramón. Para descolonizar os estudos de economia política e os estudos pós - coloniais: transmodernidade, pensamento de fronteira e colonialidade global. Revista Crítica de Ciências Sociais, n. 80, p.115-147, 2008. Disponível em: https://journals.openedition.org/rccs/697\#article-697. Acessado em 27.04.2021.

IPEA/FBSP. Atlas da Violência. Homicídio de Mulheres. Instituto de Pesquisa Econômica Aplicada / Fórum Brasileiro de Segurança Pública, 2021. Disponível em https://www.ipea.gov.br/atlasviolencia/dados-series/40. Acesso em 28.04.2021.

IPEA;FBSP. Instituto de Pesquisa Econômica Aplicada; Fórum Brasileiro de Segurança Pública (org.). Atlas da violência 2019. Brasília; Rio de Janeiro; São Paulo: IPEA; FBSP, 2019.

JESUS, Jaqueline Gomes de.Transfobia e crimes de ódio: Assassinatos de pessoas transgênero como genocídio. História Agora, v.16, n.2, p.101-123, 2013. Disponível em http://jaquejesus.blogspot.com/2015/08/transfobia-e-crimes-de-odio.html. Acesso em 28.04.2021.

KRAWCSUN, Natália Branco Lopes; GOMES, Magno Rogério; SOUZA, Solange de Cassia Inforzata de. Reforma Trabalhista e Desigualdade de Gênero no Brasil: uma perspectiva jurídica e econômica. In.: Revista Brasileira de Políticas Públicas, v.10, n.2, p.546562, 2020. Disponível em https://www.publicacoesacademicas.uniceub.br/RBPP/article/view/6488. Acesso em 28.04.2021.

LAGATA, Carla; BALZER, Carsten; BERREDO, Lukas. 2.190 asesinatos son sólo la punta del iceberg - una introducción al proyecto Observatorio de Personas Trans Asesinadas. Informe anual del TMM, Série de Publicações TVT [online]. Berlin, TGEU, vol.15, 2016. Disponível em https://transrespect.org/wp-content/uploads/2016/11/TvT-PS-Vol15-2016.pdf. Acesso em 28/09/2020.

LOZANO LERMA, Betty Ruth. Asesinato de mujeres y acumulación global: el caso del bello puerto del mar mi Buenaventura. In: GR UNER, Sheila et al. Des/dibujando el pais/aje. Aportes para la paz con los pueblos afrodescendientes e indigenas: territorio, autonomia y buen vivir. Medelín, Colômbia: CEPRAFO, 2016, p.73-86.

MALDONADO-TORRES, Nelson. Analítica da colonialidade e da decolonialidade: algumas dimensões básicas. In.: BERNARDINOCOSTA, Joaze; MALDONADO-TORRES, Nelson; GROSFOGUEL, Ramón. Decolonialidade e pensamento afrodiaspórico. Belo Horizonte: Autêntica Editora, 2019, cap.2, p.27-54.

MENEGHEL, Stela Nazareth; LOZANO LERMA, Betty Ruth. Feminicídios em grupos étnicos e racializados: síntese. Ciênc. saúde coletiva, Rio de Janeiro, v.22, n.1, p.117-122, 2017. Disponível em http://www.scielo.br/scielo.php?script=sci_arttext\&pid=S1413$81232017000100117 \& \operatorname{lng}=$ pt\&nrm=iso\&tlng=PT. Acesso em 15.10.2020.

MOTTA, Filipe; CAMPOS, Bárbara Lopes. Estado de bem - estar social e políticas públicas para mulheres nos países nórdicos e na América Latina: Da sociedade civil à institucionalização. Sex., Salud Soc., Rio de Janeiro, n. 33, p.158-179, 2019. Disponível em http://www.scielo.br/scielo.php?script=sci_arttext\&pid=S1984-64872019000300158\&lng=en\&nrm=iso. Acesso em 11.11.2020.

NOGUEIRA, Sayonara Naider Bonfim; AQUINO, Tathiane Araújo; CABRAL, Euclides Afonso. Dossiê: a geografia dos corpos das pessoas trans. Rede Trans Brasil: 2017. 
PRATES, Jane Cruz. O método marxiano de investigação e o enfoque misto na pesquisa social: uma relação necessária. In.: Textos \&

$\begin{array}{llllll}\text { Contextos, } & \text { Porto } & \text { Alegre, } & \text { v.11, } & \text { n.1, } & \text { p.116-128, }\end{array}$ https://repositorio.pucrs.br/dspace/bitstream/10923/7985/2/O_metodo_marxiano_de_investigacao_e_o_enfoque_misto_na_pesquisa_ social_uma_relacao_necessaria.pdf. Acesso em 28.04.21.

QUIJANO, Aníbal. Colonialidade do poder, eurocentrismo e América Latina. In.: LANDER, Edgardo (org.). A colonialidade do saber: eurocentrismo e ciências sociais. Perspectivas latino-americanas. Colección Sur Sur, CLACSO: Ciudad Autónoma de Buenos Aires, Argentina, 2005,p.227-278.

SAGOT, Montserrat. Ruta critica de las mujeres afectadas por la violencia intrafamiliar en América Latina: estudios de caso de diez paises. Washington, D.C.: OPAS, 2000.

SANTOS, Roseniura. A reforma trabalhista sob a regência do projeto Doing Business do Banco Mundial: a investida ultraliberal do Governo Temer. In.: Cadernos do CEAS, Salvador/Recife, n.242, p.541-557, 2017. Disponível em https:/cadernosdoceas.ucsal.br/index.php/cadernosdoceas/article/view/393. Acesso em 28.04.2021.

SANTOS, Beatriz Abreu dos; RINALDI, Patrícia Nogueira. Os impactos sociais, econômicos e internacionais do mercado global de cocaína nas Américas. In.: RINALDI, Patrícia Nogueira (cord.). A difusão de poder na economia globalizada: estados, empresas transnacionais e cartéis de drogas na América Latina. Campinas: [s.n.], 2011, cap.4, p.97-129. Disponível em http://dadosabertos.presidencia.gov.br/dataset/25fa81bb-c624-4bdb-a9af-6f28c7e 868f4/resource/11f9884d-8fdd-420e-bcb02772a1cbe621/download/ofta_2011_etn_e_narcotrafico2011.pdf. Acesso em 28.04.2021.

SEGATO, Rita Laura. Território, soberania e crimes de segundo Estado: a escritura nos corpos das mulheres de Ciudad Juarez. Revista Estudos Feministas, Florianópolis, v.13, n.2, p.265-285, maio/ago. $2005 . \quad$ Disponível em https://www.scielo.br/pdf/ref/v13n2/26882.pdf. Acesso em 27/09/2020.

SOLBERG et al. Primeiros Ministros Nórdicos: Estamos comprometidos em proteger o direito das mulheres. Diálogos Nórdicos, 08.03.2020. Disponível em https://www.dialogosnordicos.com/post/primeiros-ministros-n\%C3\%B3rdicos-estamos-comprometidos em-proteger-os-direitos-das-mulheres. Acesso em 28.04.2021.

TORRE, Ana Karen de la. No México, feminicídios subiram 137\% nos últimos 5 anos. LexLatin, 08.03.2020. Disponível em https://br.lexlatin.com/reportagens/no-mexico-feminicidios-subiram-137-nos-ultimos-cinco-anos. Acesso em 28.04.2021.

UNICEF. The Millennium Development Goals Report 2015. UNITED NATIONS, $2015 . \quad$ Disponível em: http://mdgs.un.org/unsd/mdg/Resources/Static/Products/Progress2015/English2015.pdf. Acesso em:24.04.2021.

UNICEF/CEPAL. Feminicídio ou femicídio. Observatório de Igualdade de Gênero da América Latina e do Caribe, 2021. Disponível em https://oig.cepal.org/pt/indicadores/feminicidio-ou-femicidio. Acesso em 28.04.2021.

VISENTINI, Paulo Fagundes. Eixos do poder mundial no século XXI:Uma proposta analítica. Austral: Revista Brasileira de Estratégia e Relações Internacionais, vol. 8, n. 15, p.9-25, 2019. Disponível em https://www.seer.ufrgs.br/austral/article/viewFile/91767/52900. Acesso em 28.04.2021.

\begin{tabular}{ll}
\hline Funções de colaboração exercidas & \\
\hline Kathleen Kate Dominguez Aguirre: & $\begin{array}{l}\text { Conceituação; Metodologia; Curadoria de dados; Administração do projeto; Visualização; Análise formal; Recursos; Obtenção de } \\
\text { financiamento; Investigação; Escrita (primeira redação); Escrita (revisão e edição); }\end{array}$ \\
\hline Informações fornecidas pelos (as) autores (as) de acordo com a Taxonomia de Funcões de Colaborador (CRediT)
\end{tabular}

